\title{
Gestão do conhecimento e sustentabilidade: Aplicações e práticas em uma pequena
}

\section{empresa}

\author{
Knowledge and sustainability management: Applications and practices in a small business \\ Gestión del conocimiento y sostenibilidad: Aplicaciones y prácticas en una pequeña empresa
}

Recebido: 22/04/2021 | Revisado: 01/05/2021 | Aceito: 06/05/2021 | Publicado: 21/05/2021

\author{
Rhubens Ewald Moura Ribeiro \\ ORCID: https://orcid.org/0000-0002-8970-6864 \\ Centro Universitário Santo Agostinho, Brasil \\ E-mail: rhubens.ribeiro@gmail.com \\ Vitória Meneses Leite \\ ORCID: https://orcid.org/0000-0002-9583-4889 \\ Centro Universitário Santo Agostinho, Brasil \\ E-mail: vitoriameneses@ hotmail.com
}

\begin{abstract}
Resumo
As pequenas empresas carecem de profissionais e estratégias com base técnica e/ou científica, além do fato de que para atuarem com destaque no ramo de treinamento e consultoria, as mesmas precisam ter boas práticas internamente. A presente pesquisa objetivou analisar como a gestão do conhecimento (GC) pode contribuir para o alcance da sustentabilidade em organizações (SEO). Como metodologia lançou-se mão de abordagem qualitativa com pesquisa descritiva e analítica, de caráter aplicado e perspectiva transversal, com estratégia de estudo de caso único, a coleta de dados com pesquisa documental e observação direta, aplicando-se a análise de conteúdo. Como resultado principal foi possível observar na prática como a GC pode ser utilizada para subsidiar uma organização no caminho para garantir a sustentabilidade organizacional.
\end{abstract}

Palavras-chave: Estratégia; Gestão do conhecimento; Pequena empresa; Sustentabilidade em organizações.

\begin{abstract}
Small companies lack professionals and strategies with a technical and / or scientific basis, in addition to the fact that in order to act with prominence in the field of training and consulting, they need to have good practices internally. This research aimed to analyze how knowledge management (KM) can contribute to the achievement of sustainability in organizations (SEO). As a methodology, a qualitative approach was used with descriptive and analytical research, of an applied character and cross-sectional perspective, with a single case study strategy, data collection with documentary research and direct observation, applying content analysis. As a main result, it was possible to observe in practice how KM can be used to subsidize an organization along the way to ensure organizational sustainability.

Keywords: Strategy; Knowledge management; Small business; Sustainability in organizations.

\section{Resumen}

Las pequeñas empresas carecen de profesionales y estrategias con base técnica y/o científica, además de que para actuar con protagonismo en el ámbito de la formación y la consultoría, necesitan tener buenas prácticas a nivel interno. Esta investigación tuvo como objetivo analizar cómo la gestión del conocimiento (KM) puede contribuir al logro de la sostenibilidad en las organizaciones (SEO). Como metodología se utilizó un enfoque cualitativo con investigación descriptiva y analítica, de carácter aplicado y perspectiva transversal, con una estrategia de estudio de caso único, recolección de datos con investigación documental y observación directa, aplicando análisis de contenido. Como resultado principal, fue posible observar en la práctica cómo se puede utilizar la GC para subsidiar una organización en el camino para asegurar la sostenibilidad organizacional.
\end{abstract}

Palabras clave: Estrategia; Conocimiento administrativo; Pequeños negocios; Sostenibilidad en las organizaciones.

\section{Introdução}

Mundo moderno, mudanças constantes, tecnologia inovadora, organizações digitais, novos conhecimentos, novas ferramentas, novos modelos de negócios, mudanças no comportamento do consumidor, aprendizagem organizacional, capacidades dinâmicas, conhecimento tácito e explícito, treinamento, capacitação, desempenho, ética, sustentabilidade, inovação, desenvolvimento tecnológico e gestão de pessoas são alguns dos caminhos para tornar as organizações mais 
competitivas e perenes em suas trajetórias entre outras variáveis tem impactado de maneira cada vez mais intensa a capacidade competitiva das organizações.

É neste mundo, cada vez mais tecnológico, que se revela crítica a concepção e desenvolvimento de novas estratégias e contínua qualificação dos recursos humanos, tendo em vista que o conhecimento tem sido um diferencial no mercado para tornar as organizações mais preparadas para a competição no mundo dos negócios (Paulino, Ribeiro, Lima, \& Ribeiro Filho, 2020).

Releva-se a oportunidade estratégica em se desenvolver estratégias eficientes, eficazes e efetivas que possam contribuir com a sustentabilidade organizacional seja de organizações públicas, privadas ou do terceiro setor.

Para aprofundar a pesquisa que aqui se apresenta, foi utilizado o seguinte problema de pesquisa: Como a gestão do conhecimento pode contribuir para o alcance da sustentabilidade organizacional? E para nortear e direcionar a mesma, foi estabelecido como objetivo principal analisar como a gestão do conhecimento (GC) pode contribuir para o alcance da sustentabilidade em uma pequena empresa. Como metodologia lançou-se mão de abordagem qualitativa, com pesquisa descritiva e analítica, de caráter aplicado, de perspectiva temporal transversal, com estratégia de estudo de caso único, sendo a técnica de coleta de dados a pesquisa documental e observação direta, submetendo os dados coletados à análise de conteúdo, bem como organização e análise sistemática para inferências.

O artigo está estruturado de forma a garantir uma leitura e relato de pesquisa claro e completo, apresentando no primeiro tópico a introdução que aqui se encerra. Segue-se com o referencial teórico que aborda a Gestão do Conhecimento (GC), Estratégia e Sustentabilidade em Organizações (SEO). Já no tópico seguinte descreve-se os caminhos metodológicos adotados. No tópico de análise e discussão dos resultados é trazida a perspectiva da Gestão do Conhecimento como estratégia alicerce para a Sustentabilidade em Organizações (SEO) onde se analisa a realidade de uma pequena empresa real. Por fim, o tópico de conclusão relata a importância do estudo, sugestões e fechamento da pesquisa, seguida das referências utilizadas.

\section{Gestão do Conhecimento - GC}

A Gestão do Conhecimento (GC) deve ser utilizada em organizações desde seu nascimento, desta forma o crescimento será sustentado por bases sólidas em conhecimento. Com isso, a organização, seja de que porte for, tornar-se-á mais competitiva na medida em que cria processos contínuos, fluídos, ricos em informações e alinhadas com a realidade organizacional. Um dos pontos importantes é entender que o capital intelectual é de suma importância, pois o conhecimento está nas pessoas e é necessário identificar e descobrir como usar esse conhecimento a favor da empresa (Paulino, Ribeiro, Lima, \& Ribeiro Filho, 2020).

O objetivo geral da GC é maximizar a eficácia e o retorno de seus ativos de conhecimento relacionados à organização, buscando a renovação permanente. Dessa forma, a GC é vista como importante para o desempenho organizacional, uma vez que desenvolve facilitadores que contribuem para o andamento e desempenho organizacional ocorrerem de forma satisfatória. Portanto, entende-se que quando a GC necessita ser estimulada e incentivada pelos líderes, com a aplicação de práticas de gestão envolvendo as pessoas, as quais são as únicas detentoras do conhecimento (Telles \& Mozzato, 2020).

Pesquisas revelam que as organizações criam conhecimento por meio das diversas interações entre os tipos de conhecimento (explícito e tácito) que por sua vez, tais interações são conhecidas como conversão do conhecimento, algo que ocorre conforme espiral do conhecimento (Oliveira, Araújo, \& Rodrigues, 2008).

A organização, seja de qual porte for, deve ser capaz de captar, armazenar e transmitir o novo conhecimento organizacional criado a partir da transformação do conhecimento tácito (pessoal e informal) em conhecimento explícito (formal e sistemático). Isso deve ser feito de maneira perene e rotineira para fortalecer os processos de aprendizagem organizacional (Nonaka \& Takeuchi, 1997). 
O conhecimento pode ser visto como público se o mesmo estiver disponível e acessível, ou seja, é uma característica do conhecimento do tipo explícito, permitindo que seja ensinado, replicado e compartilhado. Já o tido como conhecimento pessoal, próprio do indivíduo, é mais completo e complexo, encontra-se na mente dos indivíduos e, por isso, é do tipo tácito, mas é o mais difícil de ser acessado em decorrência da complexidade envolvida na externalização do mesmo (Azevedo, Brito, Rocha Neto, \& Araújo, 2020; Nolasco, Azevedo, Guimarães, \& Barreto, 2020).

A administração geral precisa estabelecer as áreas para as quais os colaboradores devem direcionar seus esforços de aprendizagem (foco), definir as metas (estratégia) e instituir elementos culturais voltados à inovação, aprendizado e comprometimento (motivação). Para tanto, deve haver compartilhamento do conhecimento dos cargos mais elevados para todos os setores da empresa, bem como o conhecimento deve fluir em todas as direções, seja de cima para baixo, de baixo para cima ou horizontalmente entre colegas de trabalho e setores (Zonzini, 2014).

Assim, para que o conhecimento organizacional seja criado, é preciso converter os conhecimentos tácito e explícito por meio de quatro processos pelos quais o conhecimento individual é "amplificado" na organização através de um processo social entre indivíduos. E pode ser ilustrado como acontece pelo Modelo SECI (Socialização, Externalização, Combinação e Internalização). Tal processo é um estimulador e produtor de conhecimento, competências e, consequentemente, de aprendizagem organizacional se bem gerido. (Strauhs, Pietrovski, Santos, Carvalho, Pimenta, \& Penteado, 2012; Zangiski, Lima, \& Costa, 2009). É possível compreender um pouco mais o processo SECI ao observar a espiral do conhecimento, apresentada na Figura 1 a seguir.

Figura 1 - Espiral do Conhecimento.

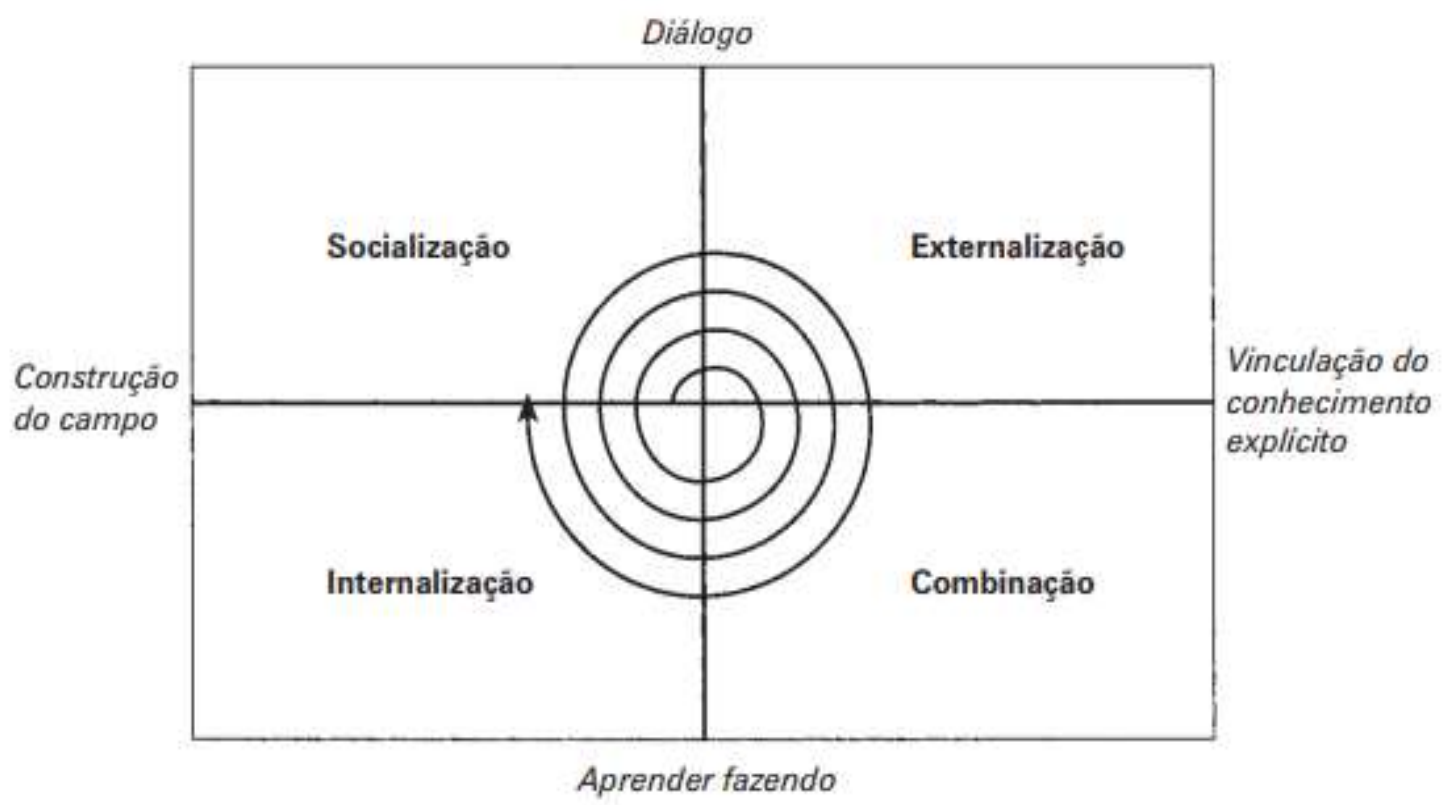

Fonte: Takeuchi e Nonaka (2008)

A socialização, por exemplo, é similar no conteúdo à teoria dos processos de grupo e da cultura organizacional. Já a combinação tem suas raízes no paradigma do processamento da informação. Por sua vez, a internalização está intimamente ligada com a organização do aprendizado. E, por último, a externalização, no entanto, tem sido amplamente negligenciada na literatura organizacional (Cáceres, 2018; Nonaka, 2008).

O papel das organizações, quando se fala em criação do conhecimento organizacional e o processo que a envolve, é criar, promover e gerenciar o ambiente apropriado para permitir que as atividades de grupo ocorram de maneira mais 
facilitada, bem como a geração e assimilação de conhecimento por todos os empregados em nível individual (Escrivão \& Silva, 2011; Nonaka \& Takeuchi, 1997, 2008; Paulino, Ribeiro, Lima, \& Ribeiro Filho, 2020).

É neste modo que o conhecimento tácito, que é pessoal, específico ao contexto e difícil de formalizar e comunicar aos outros, é convertido em conhecimento transmissível e articulado. Quando a expressão adequada não pode ser encontrada, as metáforas e analogias tornam-se ferramentas úteis. As metáforas oferecem uma forma para que os indivíduos, baseados em outros contextos e com experiências diferentes, compreendam algo intuitivamente através do uso da imaginação e dos símbolos. As analogias esclarecem como duas ideias ou objetos são semelhantes ou não-semelhantes e, portanto, propiciam um passo intermediário entre a imaginação pura e o raciocínio lógico (Sousa \& Ribeiro, 2018; Takeuchi \& Nonaka, 2008).

Como forma de estruturar a gestão do conhecimento em nível organizacional para que seja contínuo, é possível fazer uso da educação corporativa. Tal estratégia auxilia a administração geral no caminho rumo à gestão do conhecimento institucionalizada e transparente. Ao adotar-se a educação corporativa implementando, por exemplo, uma universidade corporativa, permite que todos os empregados da organização percebam o quão relevante é a capacitação, treinamento, aprendizado e desenvolvimento de competências para a organização como um todo, em todos os níveis hierárquicos (Brandão, 2006; Moscardini \& Klein, 2015; Vargas, 2003).

\section{Estratégia}

Estratégia é o caminho a ser seguido, é a orientação e o alcance das organizações ao longo do tempo. Por meio dela se conquistam vantagens frente aos ambientes inconstantes do mundo dos negócios, desde que se adote a configuração de recursos e competências otimizada para a realidade imposta e que permita atender às expectativas dos stakeholders. Devido a tal realidade tão múltipla é que as estratégias adentram o campo da diversificação apresentando sub classificações para um melhor encaixe nas realidades organizacionais distintas (Johnson, Scholes, \& Whittington, 2011).

Existem os mais diversos conceitos sobre estratégia, focando em ações realizadas ou à realizar. Devido a tal multiplicidade, o conceito de estratégias genéricas surgiu com o intuito de agrupar entendimentos de maneira ampla para se criar uma tipologia aplicável e replicável nas mais diversas organizações seja qual for seu estágio de desenvolvimento. A importância da utilização de tais tipologias reduz o número de possíveis combinações que um estudioso precisaria contemplar em suas análises bem como, tais categorias acabam por representar caracteres gerais e amplos de forma a definirem um pacote mais holístico de atributos. Existe uma tipologia muito conhecida denominada de estratégias genéricas, as quais são relacionadas ao direcionamento geral que a organização dá ao seu negócio, são elas: liderança no custo total (custos), diferenciação e enfoque (Carneiro, Cavalcanti, \& Silva, 1997; Porter, 1980, 1985; \& Royer, 2010).

Com base na tipologia das estratégias genéricas de Porter, acreditava-se que só obteria sucesso a empresa que conseguisse aplicar uma das três estratégias genéricas para direcionar os rumos frente ao mercado de forma a se destacar da concorrência. Porém, a realidade tem mostrado que as organizações podem adotar uma estratégia genérica exclusivamente, mas também podem adotar modelo híbrido de combinação das mesmas conforme a realidade enfrentada (Carneiro, Cavalcanti, \& Silva, 1997).

Outra taxonomia adota a diferenciação como base para classificar os tipos de estratégias e apresenta um nível de detalhamento mais profundo que o de Porter. São derivadas do conceito de diferenciação e classificadas como: preço, imagem, suporte, qualidade, design (projeto) e não-diferenciação (Mintzberg, 1988).

A estratégia em nível de negócios serve para diferenciar a posição que uma organização ocupa da de seus concorrentes. Para conseguir uma posição de destaque, a empresa precisa aprender a integrar suas ações de forma a criar vantagem competitiva de tal forma que culminem em criação de valor aos clientes (Hitt, Ireland, \& Hoskisson, 2008). 
O sucesso de cada estratégia adotada tem relação dependente do cenário onde se atua, das oportunidades e ameaças que se apresentam, bem como dos recursos, capacitações e competências essenciais da organização. As competências essenciais apresentam-se como fatores decisivos frente ao mercado competitivo, além de tornar a organização mais assertiva em sua atuação junto ao mercado, concorrência e stakeholders (Hitt, Ireland, \& Hoskisson, 2008; Prahalad \& Hamel, 1990).

Estratégias baseadas em inovação são chave para conduzir as organizações rumo ao futuro e perenidade de suas operações. Para criar valor aos stakeholders as organizações devem buscar o desenvolvimento de habilidades alicerçadas em processos de destruição criativa para criar um ciclo virtuoso de reinvenção que permita o atendimento de necessidades reais de tal forma que conduzam as organizações que as adotem em um ciclo de vida sustentável e salutar (Hart \& Milstein, 2003; Nobre \& Ribeiro, 2013; Ribeiro, Segatto, \& Coelho, 2013).

É fundamental, para a perenidade dos negócios, que se compreenda como são formuladas e desenvolvidas as estratégias dentro de uma organização. A estratégia possibilita o desenvolvimento do processo de interação entre ambiente, pessoas e organização. Portanto, o gerenciamento estratégico pode ser abordado por meio de diversas teorias e a multidisciplinariedade (Vicente, Rafael, Bussler, Joaquim Filho, \& Nabarreto, 2020).

Ao considerar a estratégia como a constante busca por resultados favoráveis para o negócio - ou seja, obtenção de retornos acima do normal - é razoável admitir que alguns recursos contribuem de modo significativo para alcançar esse objetivo mais do que outros. E ao adquirir, explorar e combinar recursos e capacidades, a empresa pode proporcionar aos consumidores soluções únicas de elevado valor de mercado e assim, obter vantagem frente à concorrência (Wilke \& Diettrich, 2020).

Frente a todo o cenário exposto, a economia com foco no mercado tem impulsionado as organizações no processo de estabelecimento de frame inovador, o qual permita ajustar as estratégias de negócios, por mais diversas que sejam, às necessidades da tecnologia e da competição que o mercado impõe sobre o cenário competitivo (Ribeiro, Segatto, \& Coelho, 2013).

\section{Sustentabilidade em Organizações - SEO}

Em sua maioria, as organizações são constituídas para serem perpétuas, ou seja, para se eternizarem nas sociedades de uma forma geral. Sendo assim, é oportuna a compreensão de aspectos, fatores, estratégias, cenários e caminhos que venham a auxiliar na tomada de decisão dos gestores para tornarem suas organizações perenes. Mas, não é suficiente apenas existir e lucrar a qualquer custo, é imprescindível que tais instituições atuem de maneira sustentável e contribuam para o equilíbrio do Triple Bottom Line (TBL) (Elkington, 2012; Hart \& Dowell, 2010; Lins \& Zylberstajn, 2010; Nobre \& Ribeiro, 2013; Ribeiro, 2013).

Com isso, a sustentabilidade em organizações passou a ser compreendida como o resultado da gestão que despende igual valor às questões social, ambiental e econômica. Nesse cenário, tais organizações tornam-se agentes participantes e estimulantes do desenvolvimento sustentável ao criarem estratégias que alicerçam condutas e ações alinhadas e direcionadas para a concretização de objetivos e a satisfação de critérios da sustentabilidade de uma maneira sistêmica (Hart, 2006; Nobre \& Ribeiro, 2013; Nobre, Walker, \& Ribeiro, 2019).

$\mathrm{O}$ ato da empresa investir em sustentabilidade faz com que o volume de negociação de suas ações se modifique a ponto de possibilitar retornos anormais ou não. Consideram-se informações dessa natureza como sendo de grande relevância na formação de preços de ativos, de maneira que estas deverão ser refletidas nos preços das ações das organizações (Silva \& Callado, 2020).

Em meio às discussões, surge o conceito do Triple Bottom Line (TBL) que busca o alinhamento e equilíbrio dos 3P’s (People, Planet e Profit) Pessoas, Planeta e Lucro. Para isso, propõe um enfoque misto e harmonioso entre as perspectivas 
ambiental, social e econômica para atuação das organizações de maneira salutar e que permita a geração de externalidades positivas em quantidade e qualidade superior às externalidades negativas (Elkington, 1994; Lins \& Zylberstajn, 2010).

A atuação com base no TBL permite a adoção de ações e estratégicas para atuar em três frentes gerais: Econômica, objetivando a criação de empreendimentos viáveis, lucrativos e atraentes financeiramente para os investidores; Ambiental, que almeja a interação de processos, práticas e relações com o meio ambiente sem lhe imputar danos permanentes; e Social, a qual despende atenção para estabelecer ações justas para trabalhadores, parceiros e sociedade. Porém, a atuação em um ou dois pilares juntos não é suficiente, pois somente a atuação nos três pilares de forma equitativa resultaria no alcance da sustentabilidade de fato (Elkington, 1994; Oliveira, Medeiros, Terra, \& Quelhas, 2012; Ribeiro, Sousa, \& Duarte, 2019).

O TBL destacou-se como proposta viável de atuação ao criar um modelo que balizaria a aplicação do tema, tornandoo atrativo para as organizações que ainda não haviam se sensibilizado. De tal maneira que muitas organizações passaram a comunicar seus desempenhos tríplices (econômico, ambiental e social) e as inter-relações decorrentes, baseadas neste conceito (Bellen, 2006; Elkington, 1994, 1998, 2004, 2012; Isenmann, Bey, \& Welter, 2007).

Estas três formas estratégicas são formas alternativas para que as empresas se defendam das forças competitivas que modelam o ambiente de negócio. A busca de uma posição intermediária é entendida pelo mercado como indefinição da empresa com relação ao seu posicionamento estratégico, o que traz mais problemas do que soluções (Royer, 2010).

Uma forma de aplicação do TBL pode ser conseguida por meio da adoção do modelo de Criação de Valor Sustentável (CVS), o qual propõe o desenvolvimento e uso de estratégias de sustentabilidade - Combate à Poluição/CP, Gerenciamento do Produto/GP, Base da Pirâmide/BP e Tecnologia Limpa - LP (Hart, 2006; Hart \& Milstein, 2003). E aqui se revela a usabilidade da Gestão do Conhecimento (GC) como conexão e fomento de todas as novas ações, aprendizados, experiências, novas abordagens, novas capacidades, novas estratégias, etc (Paulino, Ribeiro, Lima, \& Ribeiro Filho, 2020).

A atuação de uma instituição que adota as três dimensões do TBL conjuntamente e as aplica em harmonia, ao reconhecer a importância igual das três, proporciona uma simbiose e maiores chances de sucesso no alcance de seus objetivos, bem como da real sustentabilidade organizacional. Como os cenários mudam com certa frequência trazendo novas variáveis para a análise e atuação organizacional, faz-se oportuno o desenvolvimento de capacidades dinâmicas que permita que uma organização permute suas formas de atuação conforme configuração do cenário imposto (Nobre \& Ribeiro, 2013; Pospichil, Froehlich, Nodari, Schmidt, \& Machado, 2020; Teece, Pisano, \& Shuen, 1997).

\section{Metodologia}

\subsection{Caracterização do estudo}

O problema de pesquisa em conjunto com os objetivos a serem alcançados pela pesquisa demandou a utilização de pesquisa do tipo analítico-descritiva, de abordagem qualitativa, natureza aplicada, com perspectiva temporal transversal, tendo como estratégia de pesquisa o estudo de caso único, junto à técnica de coleta de dados a ser realizada por meio de pesquisa de campo com base em pesquisa documental e observação direta, sendo feito uso de análise de conteúdo como método de análise dos dados (Bardin, 2009; Creswell, 2010; Gil, 2002, 2008; Martins \& Theóphilo, 2009; Takahashi, 2013; Vergara, 2004; Yin, 2005; Zanella, 2013).

\subsection{Amostra, critérios de inclusão e exclusão}

A pesquisa foi desenvolvida em uma pequena empresa de consultoria empresarial e treinamento, a qual tem como público outras empresas, empresários e profissionais que buscam consultoria em organizações e/ou treinamentos na área empresarial. 


\subsection{Procedimentos de coleta}

Lançou-se mão de pesquisa documental e observação direta como técnicas de coleta de dados para enriquecer e sanar as necessidades de dados e informações a serem analisadas. O desenvolvimento geral da pesquisa se deu em dois momentos onde o primeiro momento foi composto por pesquisa documental (Quadro 1), recolhendo dados referentes ao planejamento, rotina, estratégias e práticas relacionadas à gestão do conhecimento que basearam as análises e inferências. As informações coletadas visaram somente conhecer as peculiaridades da organização em relação à sua constituição e funcionamento.

Quadro 1 - Protocolo de Pesquisa Documental.

\begin{tabular}{|c|l|}
\hline DOCUMENTO & \multicolumn{1}{|c|}{ DADO E/OU INFORMAÇÃO A SER COLETADA } \\
\hline $\begin{array}{c}\text { Planejamento } \\
\text { Estratégico }\end{array}$ & $\begin{array}{l}\text { Existência, temporalidade, amplitude, modelo, áreas contempladas, ferramentas utilizadas, exequibilidade, } \\
\text { gestão do conhecimento, etc; }\end{array}$ \\
\hline Mapa Estratégico & Existência, imagem, constituição, componentes, alinhamento, exequibilidade, gestão do conhecimento, etc; \\
\hline Projetos Estratégicos & Existência, quantidade, alinhamento, componentes, gestão do conhecimento, etc; \\
\hline Relatórios Gerenciais & $\begin{array}{l}\text { Existência, informações contidas, modelo, ações de gestão do conhecimento, comunicação interna e externa, } \\
\text { etc; }\end{array}$ \\
\hline Planejamentos Setoriais & Existência, gestão do conhecimento, áreas contempladas, comunicação interna e externa, etc; \\
\hline $\begin{array}{c}\text { Modelo de Gestão do } \\
\text { Conhecimento }\end{array}$ & Existência, modelo adotado, planejamento das ações, etc; \\
\hline
\end{tabular}

Fonte: Autores (2021).

A segunda etapa da coleta de dados (Quadro 2) foi realizada com base em observação direta onde se buscou informações e dados acerca do funcionamento da empresa, sua organização, layout, tamanho, localização, constituição, práticas, etc.

Quadro 2 - Protocolo de Observação Direta.

\begin{tabular}{|c|l|}
\hline O QUÊE & \multicolumn{1}{|c|}{ DADO E/OU INFORMAÇÃO A SER COLETADA } \\
\hline Organização e Layout & Estrutura, espaço, tamanho, funcionamento, organização interna da empresa, etc; \\
\hline Comunicação & Canais de comunicação, processo de comunicação interna e externa, redes sociais, sites, etc; \\
\hline Localização & Endereço, fachada, facilidade de acesso, processo de escolha, etc; \\
\hline Outras informaçães & $\begin{array}{l}\text { Aplicação da gestão do conhecimento e outras informações que forem julgadas relevantes no momento da } \\
\text { observação direta. }\end{array}$ \\
\hline
\end{tabular}

Fonte: Autores (2021).

\subsection{Procedimentos de Análise}

Os dados coletados foram analisados qualitativamente por meio de organização e comparação entre teoria e prática e fazendo uso da técnica da análise de conteúdo e, para isso, os dados serão organizados, tabulados e categorizados de maneira que se possam realizar inferências sobre a realizada da empresa estudada e a gestão do conhecimento.

\subsection{Aspectos Éticos e Legais}

A pesquisa atendeu os preceitos éticos e legais enquadrando-se nas exigências éticas para realização de pesquisa científica, de tal forma que a empresa foi consultada e forneceu autorização por escrito para que os pesquisadores pudessem 
acessar todos os documentos, espaços e informações sobre a organização, bem como para fazer menção ao nome real e identificação da mesma no registro científico durante a redação do artigo a ser publicado.

Sendo assim, todos os dados divulgados possuem autorização prévia e os pesquisadores adotaram conduta responsável para não revelar informações estratégicas e/ou críticas da organização, tendo-se sempre o cuidado para que a redação do estudo contemple o todo e análises técnicas focando na ciência.

\subsection{Riscos e Benefícios}

Os riscos da pesquisa giraram em torno da possibilidade de danos à dimensão física (acidente durante a coleta de dados), moral (desrespeito ou constrangimento antes, durante ou após a visita à empresa) com exposição irresponsável de informações em qualquer fase de uma pesquisa e dela decorrente por parte dos pesquisadores. Para minimizar os possíveis riscos e danos, os pesquisadores foram treinados previamente para imersão no ambiente de estudo, de tal forma que puderam conduzir o momento da coleta sem vieses, posturas, abordagens, falas, críticas ou comentários durante a pesquisa documental e observação direta.

Em relação aos benefícios é possível mensurar que os resultados podem permitir a compreensão de como se dá o processo de concepção e execução de estratégias que contribuam com a sustentabilidade organizacional com base no uso da gestão do conhecimento. Além disso, apresentando propostas para subsidiar a concepção de estratégias para otimizar as ações da empresa baseando-se em premissas cientificamente construídas tornando ainda mais profissional a gestão e execução das suas atividades corroborando para otimização do uso dos recursos e pessoal disponível, com a melhoria do atendimento, dos serviços, dos preços, das modalidades e prazos de pagamentos, aprendizagem organizacional, da qualificação da equipe e da melhor divulgação e promoção da organização, tudo isso sendo consequência de um planejamento futuro baseado nos dados, informações, análises e inferências resultantes da pesquisa.

\section{Resultados e Discussão}

A Real Inteligência em Negócios - nome fantasia (Real Treinamento e Consultoria Empresarial - razão social) é uma empresa piauiense focada em treinamentos e consultorias, criada em 2019 e formada por Administradores entusiastas da profissionalização da gestão em organizações públicas e privadas. Com um time visionário, capacitado e multidisciplinar, a empresa surgiu vocacionada para criar soluções inteligentes para organizações que vislumbrem melhores resultados e para profissionais que busquem construir carreiras sólidas.

Trata-se uma pequena empresa que trabalha com treinamentos e consultoria empresarial, ofertando seus serviços tanto para pessoas físicas quanto jurídicas. Para iniciar suas atividades, a organização elaborou seu planejamento estratégico no final do ano de 2019 com horizonte temporal de 05 (cinco) anos, contemplando os anos de 2020 a 2024, realizando diagnóstico, aplicação de ferramentas e uso da metodologia Balanced Scorecard (BSC) proposta por Kaplan \& Norton (1992).

É relevante destacar que antes do início do desenvolvimento do planejamento estratégico, os sócios submeteram-se a capacitação prévia, cursos, estudos, pesquisas e discussão para estabelecer o formato que seria utilizado pela organização, já que o mesmo seria utilizado como exemplo de produto/serviço a ser comercializado futuramente como serviço de consultoria e treinamentos.

Outra informação relevante é que dois dos sócios assumiram a condução do processo para possibilitar aos demais sócios o conhecimento e expertise necessária para trabalharem no desenvolvimento do planejamento da empresa, pois os dois já possuíam experiência anterior específica com planejamento estratégico.

O conhecimento tácito dos sócios sobre planejamento foi submetido ao processo SECI proposto na gestão do conhecimento, onde estabeleceram diversos encontros (reuniões) para construção do planejamento estratégico da empresa. 
O diagnóstico estratégico foi desenvolvido a partir das análises conjuntas dos sócios onde foi possível socializar seus conhecimentos tácitos em discussões e debates, para em seguida passar pela externalização onde puderam registrar suas análises e unificar entendimentos transformando em conhecimento explícito passível de verificação. Em seguida, a etapa combinação foi realizada ao analisar os registros explicitados na externalização com base e confronto com metodologias e ferramentas já de amplo conhecimento público em manuais e publicações. Por fim, utilizou-se da internalização na medida em que os conhecimentos passaram a ser internalizados e transformados em tácito por cada um dos sócios envolvidos.

De maneira visual, o processo SECI aplicado na empresa está exemplificado ilustrativamente pela Figura 2 apresentada a seguir:

Figura 2 - Processo SECI.

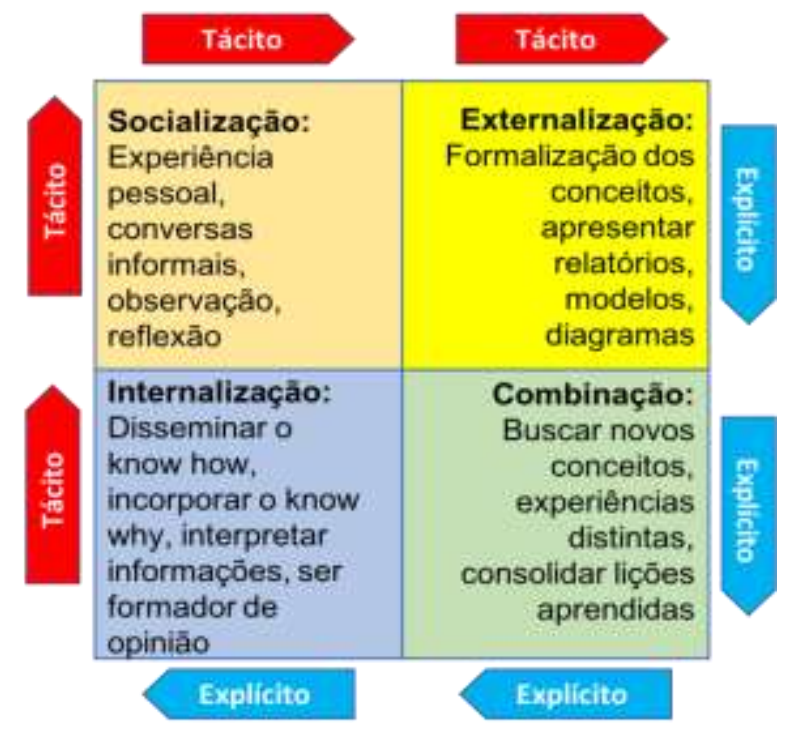

Fonte: Stonner (2018).

Como seu planejamento estratégico foi elaborado fazendo uso de diversas ferramentas de diagnóstico e da metodologia do BSC, o mesmo possui todos os elementos propostos como: apresentação, missão, visão, valores, mapa estratégico, objetivos, metas, indicadores, projetos, responsáveis e etc. Já as ferramentas de diagnóstico não aparecem no documento final, foram utilizadas apenas durante o processo de elaboração. A seguir, o Quadro 3 apresenta a missão, visão e valores da organização que foram criados pela interação e percepção dos empresários:

Quadro 3 - Missão, Visão e Valores da Real Inteligências em Negócios

\begin{tabular}{|c|l|}
\hline ELEMENTO & \multicolumn{1}{c|}{ DESCRITIVO } \\
\hline Missão & $\begin{array}{l}\text { Transformar realidades por meio do conhecimento e da prática da Administração através de consultorias, } \\
\text { treinamentos e projetos. }\end{array}$ \\
\hline Visão & $\begin{array}{l}\text { Ser referência regional na área de gestão atuando com inteligência em negócios por meio de consultorias, } \\
\text { treinamentos e elaboração de projetos que permitam a gestores, profissionais, empresários e estudantes acesso } \\
\text { ao conhecimento científico e funcional. }\end{array}$ \\
\hline Valores & $\begin{array}{l}\text { 1- Ética nos Negócios; 2- Conhecimento; 3- Inovação em Negócios; 4- Qualidade em Serviços; 5- } \\
\text { Responsabilidade Socioambiental }\end{array}$ \\
\hline
\end{tabular}

Fonte: Real (2020). 
Como foi feito uso da metodologia BSC, foi elaborado um mapa estratégico contemplando todos os componentes previstos, sendo assim, é dotado de missão, visão, valores, perspectivas e objetivos estratégicos, os quais foram concebidos em harmonia com a proposta de negócios e estratégias da organização.

É oportuno observar que a empresa objeto de estudo apresenta em seu mapa estratégico quatro perspectivas, sendo uma delas a denominada "Gestão do Conhecimento e Desenvolvimento", a qual prevê em seus objetivos a capacitação continuada e engajamento de seus recursos humanos, a criação e implantação de um modelo de gestão do conhecimento que atenda às necessidades da organização e o desenvolvimento de um método de consultoria próprio.

Tudo isso, demonstra que a organização adotou a gestão do conhecimento como uma das estratégias alicerça ntes da sustentabilidade organizacional, pois a mesma é a perspectiva presente na base do mapa estratégico e que dá suporte às demais perspectivas (como se pode ver na Figura 3), além de que o método de consultoria próprio previsto em um dos objetivos estratégicos só poderá ser concebido após aplicação com sucesso da gestão do conhecimento (GC).

Figura 3- Mapa Estratégico da Real Inteligência em Negócios.

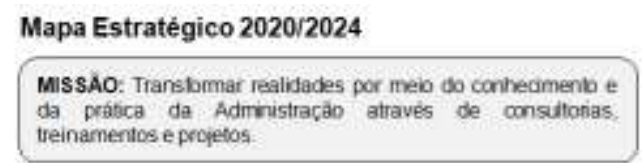

VISĀO DE FUTURO Ser referenda regional na área de gestào atuando com imeligenda emnegócios por meio de consullonias, ternamentas e eliboracio de projelos que permilam a gestores, profissionais, emvresácos e estudartes acesso ao conhecimento cientifico e funcional
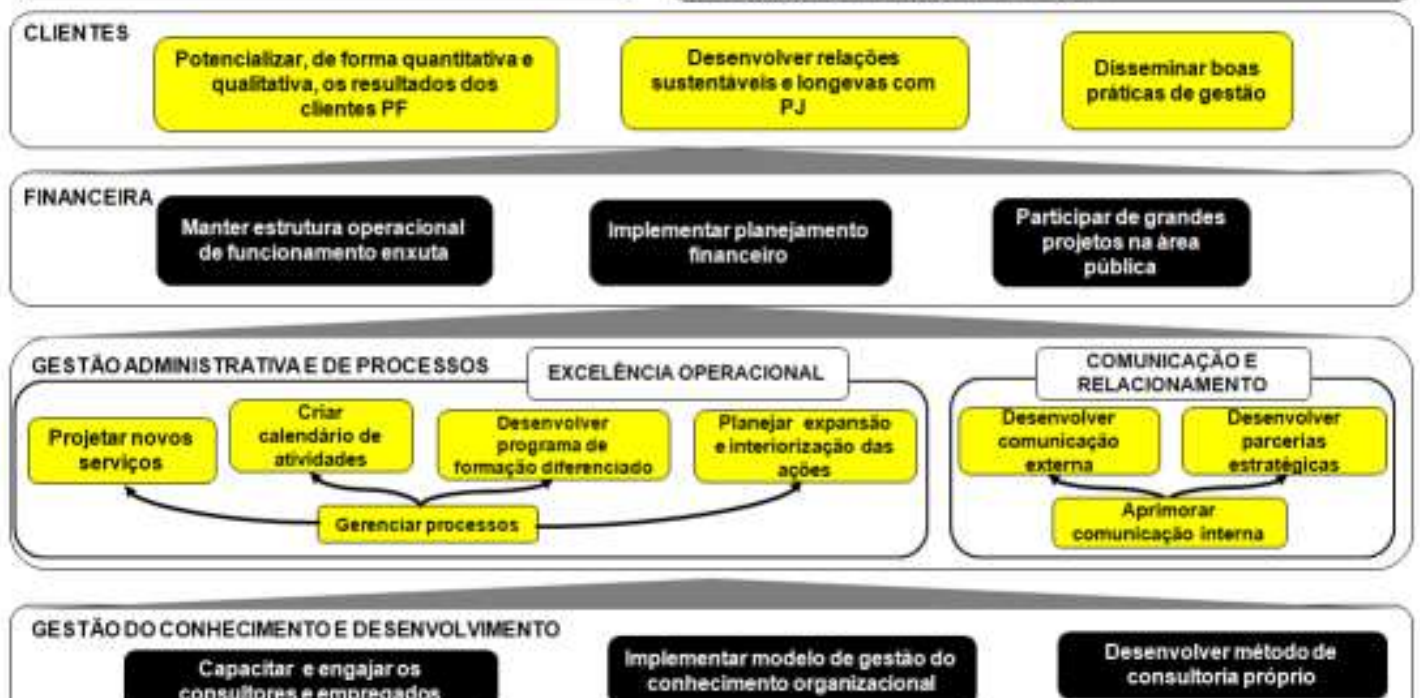

Desenvolver metodo de consultoria próprio

\begin{tabular}{|c|c|c|c|c|c|c|}
\hline VALORES & Realinteígencia em Negocios & $\begin{array}{l}\text { ERca Nos } \\
\text { MEcocios }\end{array}$ & comiecauento. & $\begin{array}{l}\text { NovaçÁo zu } \\
\text { Nereocias }\end{array}$ & 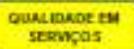 & 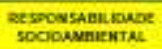 \\
\hline
\end{tabular}

Fonte: Real (2020).

Seu mapa estratégico foi desdobrado em metas e indicadores que contemplam todos os objetivos estratégicos previamente estabelecidos. Tendo um indicador para cada objetivo e metas anuais referentes a cada ano do horizonte temporal (2020-2024). O desdobramento foi todo elaborado em planilha do Excel de forma a ser mais acessível por todos os sócios e visualização condensada completa e para que possa servir continuamente à gestão organizacional, bem como para que a gestão do conhecimento seja aplicada no dia a dia da empresa ao prever revisões periódicas no documento construído. Um recorte da planilha matriz pode ser observado na Figura 4 apresentada a seguir: 
Figura 4 - Desdobramento do Mapa Estratégico com Metas e Indicadores.

\begin{tabular}{|c|c|c|c|c|c|c|c|c|c|c|c|c|c|}
\hline$\stackrel{\infty}{\gtrless}$ & & & & & & & & |ᄃר & & & PR & ZOS & 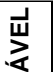 \\
\hline $\begin{array}{l}\bar{n} \\
\frac{\pi}{4} \\
\text { 品 }\end{array}$ & ESTRATEGICOS & n & & ก) & న & & & INDICADOR & & PROJETO & INÍCIO & |TÉRMINO & $\begin{array}{l}\text { 品 } \\
\text { ॠ }\end{array}$ \\
\hline $\begin{array}{l}0 \\
\stackrel{2}{1}\end{array}$ & $\begin{array}{l}\text { Capacitar e engajar } \\
\text { os consultores e } \\
\text { empregados }\end{array}$ & $100 \%$ & & & & & Engajamento & & $\begin{array}{l}\text { Envolvimento } \\
\text { Real }\end{array}$ & & Março & Dezembro & \\
\hline 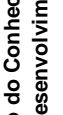 & $\begin{array}{l}\text { Implementar modelo } \\
\text { de gestão do } \\
\text { conhecimento } \\
\text { organizacional }\end{array}$ & criar & & & & & $\begin{array}{c}\text { Gestão do } \\
\text { conhecimento }\end{array}$ & & $\begin{array}{c}\text { Projeto Banco de } \\
\text { Conhecimento }\end{array}$ & & Julho & Dezembro & \\
\hline రँ & $\begin{array}{l}\text { Desenvolver método } \\
\text { de consultoria próprio }\end{array}$ & criar & & & & & Método REAL & & $\begin{array}{c}\text { Projeto Método } \\
\text { Real }\end{array}$ & & Janeiro & Julho & \\
\hline
\end{tabular}

Fonte: Real (2020)

A Figura 4 apresentada anteriormente foi deliberadamente modificada (pintada de preto) em alguns locais para não revelar informações estratégicas da organização. Mesmo assim, é possível observar que a gestão do conhecimento se faz presente com seus próprios indicadores, metas, projetos, temporalidade/prazos e responsáveis. Cabe destacar que os responsáveis são profissionais da empresa com maior expertise na área do objetivo estratégico para que o mesmo possa gerenciar a realização e alcance do mesmo com maior propriedade.

Em relação aos projetos estratégicos, a empresa elaborou um projeto estratégico para cada objetivo estratégico previsto em seu planejamento e mapa estratégico, de tal forma que contemplassem ações, indicadores, prazos (de início e término), responsáveis, etapas, detalhamento, equipe a ser envolvida e apoio necessário, tal qual acontece com os planos de ação como o 5W2H. Os mesmos apresentam conexão e aderência de maneira muito significativa revelando que a organização aplicou a gestão do conhecimento durante o processo de concepção de suas estratégias e planejamento estratégico. A Figura 5 apresenta o modelo adotado para os projetos estratégicos:

Figura 5 - Modelo de Projeto Estratégico.

\begin{tabular}{|c|c|c|c|c|c|}
\hline \multirow{6}{*}{$\begin{array}{c}\text { Projeto } \\
\text { Banco de } \\
\text { Conhecimen } \\
\text { to }\end{array}$} & PERSPECTIVA & \multicolumn{4}{|c|}{ Gestão do Conhecimento de Desenvolvimento } \\
\hline & OBJETIVO ESTRATÉGICO & \multicolumn{4}{|c|}{ Implementar modelo de gestão do conhecimento organizacional } \\
\hline & INDICADOR & \multicolumn{4}{|l|}{ Gestão do Conhecimento } \\
\hline & RESPONSÁVEL & \multicolumn{4}{|l|}{ 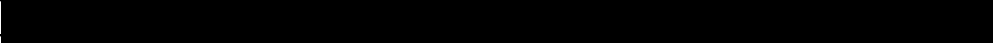 } \\
\hline & APOIO & & & & \\
\hline & VIGÊNCIA & \multicolumn{4}{|l|}{ Julho a Dezembro/2020 } \\
\hline № & ETAPAS & \multirow[t]{2}{*}{ DETALHAMENTO } & INÍCIO & TÉRMINO & ENVOLVIDOS \\
\hline 1 & & & Julho & Setembro & - \\
\hline 2 & $\begin{array}{l}\text { Desenhar o modelo de gestão do } \\
\text { conhecimento Real }\end{array}$ & & Ulho & Outubro & - \\
\hline 3 & & & Ulho & Dezembro & \\
\hline
\end{tabular}

Fonte: Real (2020). 
A Figura 5 apresentada anteriormente foi deliberadamente modificada (pintada de preto) em alguns locais para não revelar informações estratégicas da organização. Para cada objetivo estratégico foi desenvolvido detalhadamente um projeto estratégico que contempla a realidade atual, bem como as perspectivas da organização em relação ao mercado, concorrentes, atuação, público alvo e ações necessárias para que cada meta seja alcançada.

Ao se analisar o planejamento da empresa como um todo foi verificado que a gestão do conhecimento está presente e de fato é adotada como estratégia para subsidiar a toma de decisão, o desenvolvimento de ações, o treinamento e capacitação dos sócios, a orientação às equipes envolvidas, a criação de conteúdo e cursos, etc.

A empresa faz uso de plataforma digital de armazenagem, gestão documental, gestão de informações, criação de documentos, registro de ações, banco de dados, etc. Além disso, faz uso de software de criação de conteúdo/peças digitais para publicação e comunicação com o mercado e clientes potenciais.

Outra observação importante foi a realização de lives, palestras e participação em eventos online (de todos os sócios na qualidade de instrutor ou alunos) após o início do isolamento social devido medidas preventivas decorrentes da pandemia (do coronavírus) que se prolonga por todo o ano de 2020. O envolvimento em tais atividades permitiu a aplicação das premissas da gestão do conhecimento ao colocar os profissionais da empresa para praticarem e desenvolverem habilidades e competências para prestação de serviços em meio digital totalmente online.

A participação em tais atividades permitiu que os profissionais da Real pudessem vivenciar novas experiências para colocarem em prática seus conhecimentos e didática em palestras para posteriormente fossem ofertados para 2021 treinamentos em formatos diversos (presencial, online ou misto), bem como o conhecimento e treinamento em plataformas virtuais e interação com clientes potenciais para prestação de serviços de consultoria, seja presencial, online ou misto.

Os profissionais que já possuíam experiência e conhecimentos sobre as práticas no mundo digital puderam auxiliar os demais profissionais para se tornarem mais aptos na execução dos serviços atendendo às mudanças ocorridas na demanda $\mathrm{e}$ canais de prestação dos serviços. Com tais experiências foi possível adquirir mais conhecimento tácito por todos os profissionais da organização, bem como transformar em conhecimento explícito para geração e diversificação de produtos e serviços alinhados às novas demandas do mercado. Além de fortalecer o processo de gestão do conhecimento dentro da Real.

A organização estudada demonstra que a gestão do conhecimento pode ser adotada como estratégia para sustentabilidade organizacional na medida em que coloca em prática os processos, perspectivas, conceitos e modelos propostos pelos estudiosos da área de GC. A sustentabilidade em organizações pode ser observada neste processo de reinvenção das práticas empresariais para garantir a perenidade da empresa mesmo em um cenário de caos e mudanças drásticas como o vivenciado durante toda a pandemia do coronavírus com suas consequências e impactos econômicos, sociais e ambientais.

\section{Conclusão}

A pesquisa alcançou seu objetivo principal ao conseguir estudar a realidade da empresa objeto de estudo (Real Inteligência em Negócios) e analisar como ela aplicou a gestão do conhecimento para alicerçar suas ações e contribuir com a sustentabilidade organizacional.

Como principal resultado foi possível observar na prática como a gestão do conhecimento foi utilizada como base para criação do planejamento estratégico da empresa (ainda no final do ano de 2019) vislumbrando um horizonte temporal de 05 (cinco) anos (2020 a 2024). Na época de elaboração, mesmo sem ter em mente a possibilidade de ocorrência de uma pandemia de nível global, os profissionais envolvidos conseguiram dar robustez para empresa mudar, aprender e poder adotar as medidas necessárias durante a pandemia, contribuindo para a perenidade da organização ao longo do tempo. 
Como se trata de um estudo de caso único que estudou a fundo uma pequena empresa do ramo de consultoria e treinamentos empresariais, a replicação dos achados torna-se limitada inicialmente à realidade da organização em questão, mas podem ser utilizados de conhecimento e exemplo para capacitar outros profissionais e estudiosos.

Devido ao cenário gerado pela pandemia que demandou isolamento social mais rigoroso, algumas dificuldades técnicas foram enfrentadas durante a pesquisa como: acesso físico à empresa para observação e acesso aos documentos e relatórios físicos a serem analisados. Tais dificuldades foram sanadas ao se realizar poucas e rápidas visitas, bem como pelo fato de a empresa possuir quase todos os documentos em formato digital.

Sugere-se que a empresa Real Inteligência em Negócios realize mais capacitações em relação às ferramentas da gestão do conhecimento adotadas com mais frequência, de forma a não se perderem os conhecimentos adquiridos por seus profissionais continuamente, bem como que sejam transformados em relatórios textuais e esquemáticos para facilitar consultas futuras e treinamentos de novos profissionais que venham a fazer parte da empresa, ou seja, trabalhar a aprendizagem organizacional. Além disso, a empresa pode criar um curso de gestão do conhecimento baseado no aprendizado e experiência que já possui.

No que diz respeito às possibilidades futuras de pesquisa, sugere-se que a mesma seja aprofundada na organização que foi estudada e repetida anualmente para que se percebam, com uma perspectiva longitudinal, os impactos de longo prazo das ações alicerçadas e uso da gestão do conhecimento nesta pequena empresa de consultoria e treinamento empresarial. Ou mesmo que seja realidade em outra organização de porte e atuação similar, mas que não se utilize da gestão do conhecimento, para poder executar um estudo comparativo.

\section{Referências}

Azevedo, I. M., Brito, L. M. P., Rocha Neto, M. P., \& Araújo, M. V. P. (2020). Diagnóstico da Gestão do Conhecimento: Um Estu do em uma Organização da Sociedade Civil de Interesse Público. Revista de Gestão e Secretariado, 11(2), 75-97.

Bardin, L. (2009). Análise de conteúdo. (70a ed.).

Bellen, H. M. V. (2006). Indicadores de sustentabilidade: Uma análise comparativa. (2a ed.). FGV. 256p.

Brandão, G. R. (2006). Gestão de pessoas e as universidades corporativas: dois lados da mesma moeda? Revista de Administração de Empresas, 46(2), 22-33.

Cáceres, E. A. (2018). Gestão do conhecimento no departamento pós-obra. (Trabalho de Conclusão de Curso). Faculdade de Engenharia - Universidade Federal da Grande Dourados, Dourados, Mato Grosso do Sul, Brasil.

Carneiro, J. M. T., Cavalcanti, M. A. F. D., \& Silva, J. F. (1997). Porter Revisitado: Análise Crítica da Tipologia Estratégica do Mestre. Revista de Administração Contemporânea, 1(3), 7-30. http://www.scielo.br/pdf/rac/v1n3/v1n3a02.pdf. Acesso em: nov. 2020.

Creswell, J. W. (2010) Projeto de Pesquisa: Métodos qualitativo, quantitativo e misto. Artmed.

Elkington, J. (1998) Cannibals With Forks: The Triple Bottom Line of 21st Century Business. Gabriola Island: New Society Publishers.

Elkington, J. (2004) Enter the triple bottom line. In: Henriques, A., \& Richardson, J. (Ed.). The triple bottom line: does it all add up. London: EarthScan.

Elkington, J. (2012). Sustentabilidade: canibais com garfo e faca. (3a ed.). M. Books.

Elkington, J. (1994). Towards the sustainable corporation: Win-win-win business strategies for sustainable development. California Management Review, $36(2), 90-100$.

Escrivão, G, \& Silva, S. L. (2011, outubro). Teoria da Criação do Conhecimento de Nonaka: aplicações e limitações em outros contextos orga nizacionais. XXXI Encontro Nacional de engenharia de produção: Inovação Tecnológica e Propriedade Intelectual: Desafios da Engenharia de Produção na Consolidação do Brasil no Cenário Econômico Mundial, Belo Horizonte, Brasil. http://www.abepro.org.br/biblioteca/enegep2011_tn_stp_142_896_18366.pdf. Acesso em: nov. 2020.

Gil, A. C. (2002). Como elaborar projetos de pesquisa (4a ed.). Atlas.

Gil, A. C. (2008). Métodos e técnicas de pesquisa social. (6a ed.). Atlas.

Hart, S. L. (2006). O capitalismo na encruzilhada: As inúmeras oportunidades de negócios na solução dos problemas mais difíceis do mundo. (L.O da Rocha, Trad.). Porto Alegre: Bookman. 
Hart, S. L., \& Dowell, G. A. (2010, December). Natural-Resource-Based View of the Firm: Fifteen Years After. Journal of Management, 1(1).

Hart, S. L., \& Milstein, M. B. (2003). Creating sustainable value. Academy of Management Executive, 17(2), 56-67.

Hitt M. A., Ireland, R. D., \& Hoskisson, E. R. (2008). Administração estratégica: competitividade e globalização. (All Tasks, Trad.) Cengage Learning.

Isenmann, R., Bey, C., \& Welter, M. (2007). Online reporting for sustainability issues. Business Strategy and the Environment, 16(1), 487-500. http://dx.doi.org/10.1002/bse.597.

Johnson, G., Scholes, K., \& Whittington, R. (2011). Fundamentos de estratégia. (R. Dubal,Trad.). Bookman.

Kaplan, R. S., \& Norton, D. P. (1992, February). The balanced scorecard - measures that drive performance. Harvard Business Review, 70(1), 71-79. < https://steinbeis-bi.de/images/artikel/hbr_1992.pdf>.

Lins, C., \& Zylbersztajn D. (Orgs.) (2010). Sustentabilidade e geração de valor: a transição para o século XXI. Elsevier.

Martins, G. A., \& Theóphilo, C. R. (2009). Metodologia da investigação científica para ciências sociais aplicadas. (2a ed.). Atlas.

Mintzberg, H. (1988). Generic strategies: toward a comprehensive framework. In: Advances in strategic management, 5(1), 1-67. Greenwich, Conn.: Jay Press.

Moscardini, T. N., \& Klein, A. (2015). Educação Corporativa e Desenvolvimento de Lideranças em Empresas Multisite. Revista de Administração Contemporânea, 19(1), 84-106. http://dx.doi.org/10.1590/1982-7849rac20151879.

Nobre, F. S., \& Ribeiro, R. E. M. (2013). Cognição e Sustentabilidade: Estudo de Casos Múltiplos no Índice de Sustentabilidade Empresarial da M\&FBovespa. Revista de Administração Contemporânea, 17(4), 499-517.

Nobre, F.S., Walker, D., \& Ribeiro, R. (2019). Towards a Contingency View of Corporate Sustainability: Strategy and Performance. Academy of Management Annual Meeting Paper ID 10285, Session 1283, ONE. (AOM 2019).

Nolasco, D. M. de S., Azevedo, I. de M., Guimarães, L. G. de A., \& Barreto, L. K. da Silva. (2020). Produção científica em gestão de operações com temática voltada para a gestão do conhecimento. $\operatorname{ReCaPe}, 10(2), 219-245$. http://dx.doi.org/10.20503/recape.v10i2.4418.

Nonaka, I., \& Takeuchi, H. (1997). Criação do conhecimento na Empresa: como as empresas. (12a ed.). Campus.

Oliveira, V, Araújo, F, \& Rodrigues, M. (2008). Gestão do Conhecimento. IV Congresso Nacional de Excelência em Gestão. Niterói, Rio de Janeiro, Brasil. https://www.inovarse.org/artigos-por-edicoes/IV-CNEG-2008/T7_0105_0086.pdf.

Oliveira, L, Medeiros, R, Terra, P, \& Quelhas, O. (2012). Sustentabilidade: da evolução dos conceitos à implementação como estratégia nas organizações. Produção, 2(1), 70-82. 10.1590/S0103-65132011005000062. https://www.scielo.br/pdf/prod/v22n1/aop_0007_0245.pdf. Acesso em: out. 2020.

Paulino, C. L. S., Ribeiro, R. E. M., Lima, E. P. L., \& Ribeiro Filho, C. A. S. (2020). Educação corporativa como alicerce estratégico para o desempenho organizacional. In: Freiras, et al. Direito e Educação: trajetórias e conhecimentos. Autografia.

Porter, M. E. (1980). Competitive strategy: techniques for analysing industries and competitors. Free Press.

Porter, M. E. (1985). Competitive advantage: creating and sustaining competitive performance. Free Press.

Pospichil, B. C., Froehlich, C., Nodari, C. H., Schmidt, S., \& Machado, R. E. (2020). The Contribution of the Dynamic Capabilities to Promote Sustainability in Industrial and Service Companies. BASE - Revista de Administração e Contabilidade da UNISINOS, 17(2), 180-210. http://www.spell.org.br/documentos/ver/58634/a-contribuicao-das-capacidades-dinamicas-para-promover-a-sustentabilidade-em-empresas-de-industria-eservico/i/pt-br

Prahalad, C. K., \& Hamel, G. (1990, may-june). The core competence of the corporation. Harvard Business Review, 79-91.

Real. Real Treinamento e Consultoria Empresarial (Razão Social) - Real Inteligência em Negócios (Nome Fantasia), CNPJ 34.891.526/0001-20. Site: www.realin.com.br. Facebook: https://www.facebook.com/realinteligenciaemnegocios. https://www.linkedin.com/company/realnegocios/. Twitter: https://twitter.com/realnegocios 1 . Instagram: https://www.instagram.com/realnegocios/.

Ribeiro, R. E. M. (2013). Cognição e sustentabilidade: estudo de casos múltiplos no índice de sustentabilidade empresarial (ise) da BM\&F Bovespa.Dissertação (Mestrado em Administração) Programa de Pós-graduação em Administração, Universidade Federal do Paraná. Curitiba, Paraná, Brasil. https://acervodigital.ufpr.br/bitstream/handle/1884/30339/R\%20-\%20D\%20\%20RHUBENS\%20EWALD\%20MOURA\% 20RIBEIRO.pdf?sequence= 1\&is Allo wed=y.

Ribeiro, R. E. M, Segatto, A. P, \& Coelho, T. R. (2013). Inovação social e estratégia para a base da pirâmide: mercado potencial para empreendedores e pequenos negócios. Revista de Empreendedorismo e Gestão de Pequenas Empresas, 2(2), 55-72. http://www.spell.org.br/documentos/ver/30758/inovacaosocial-e-estrategia-para-a-base-da-pir---. Acesso em: nov. 2020.

Ribeiro, R. E. M., Sousa, L. H. S. S., Duarte, C. T. T. (Orgs.). (2019). Piauí Cases. (1a ed.). Teresina: Kindle Direct Publishing. https://unifsa.com.br/site/ebook-piaui-cases-esta-disponivel-para-download/.

Royer, R. (2010, outubro). As estratégias competitivas genéricas de porter e o novo paradigma da customização em massa. XXX Encontro Nacional de Engenharia de Produção. Maturidade e desafios da Engenharia de Produção: competitividade das empresas, condições de trabalho, meio ambiente. http://www.abepro.org.br/biblioteca/enegep2010_TN_STP_119_775_15122.pdf.

Silva, N. E. F., \& Callado, A. L. C. (2020). Divulgação do Ranking Global 100 e o Efeito nos retornos das Ações: Uma Abordagem Utilizando Estudo de Eventos. Advances in Scientific and Applied Accouting, 13(2), 176-192. DOI: http://dx.doi.org/10.14392/asaa.2020130209. Acesso em: nov. 2020. 
Research, Society and Development, v. 10, n. 6, e7610615359, 2021

(CC BY 4.0) | ISSN 2525-3409 | DOI: http://dx.doi.org/10.33448/rsd-v10i6.15359

Sousa, L. H. dos S. S., \& Ribeiro, R. E. M. (Orgs.). (2018). Administração e contemporaneidade no Piauí. Kindle Direct Publishing.

Stonner, R. (2018). Modelo SECI - Gestão do Conhecimento. https://blogtek.com.br/modelo-seci-gestao-do-conhecimento/.

Strauhs, F. R., Pietrovski, E. F., Santos, G. D., Carvalho, H. G., Pimenta, R. B., \& Penteado, R. S. (2012). Gestão do Conhecimento nas Organizações. In Strauhs, et al. Aymará Educação.

Takahashi, A. R. W. (Org.). (2013). Pesquisa qualitativa em administração: Fundamentos, métodos e usos no Brasil. Atlas.

Takeuchi, H, \& Nonaka, I. (2008). Gestão do conhecimento. (Thorell, Ama. Trad.). Bookman.

Teece, D. J., Pisano, G., \& Shuen, A. (1997). Dynamic capabilities and strategic management. Strategic Management Journal, 18(7), 509-533. 10.1002/(SICI)1097-0266(199708)18:7<509::

Telles, M.S., \& Mozzato, A. R. (2020). Facilitar ou Dificultar? Caminhos para a Gestão do Conhecimento. Perspectivas em Gestão \& Conhecimento, 10(1), 39-53. http://dx.doi.org/10.21714/2236-417X2020v10n1p39.

Vargas, M. R. M. (2003). Universidade corporativa: diferentes modelos de configuração. RAUSP Management Journal, 38(4), 373-379.

Vergara, S. C. (2004). Projetos e Relatórios de pesquisa em administração. (5a ed.). Atlas.

Vicente, S. C. S., Rafael, D. N., Bussler, N. R. C., Joaquim Filho, J., \& Nabarreto, R. L. (2020). Evolução da Cocitação - Estrutura Intelectual da Pesquisa em Estratégia: Uma extensão do trabalho de Ramos-Rodriguez e Ruiz-Navarro (2004). Revista Ibero-Americana de Estratégia, 9(1), 33-63. https://doi.org/10.5585/riae.v19i1.16533. Acesso em: nov. 2020.

Wilke, E. P., \& Diettrich, L. C. (2020). Recursos Estratégicos: Estudo de Caso em Hotel 'Upscale'. Reuna, 25(1), 20-34. http://dx.doi.org/10.21714/2179$8834 / 2020 \mathrm{v} 25 \mathrm{n} 1 \mathrm{p} 20-34$.

Yin, R.K. (2005). Estudo de caso: Planejamento e métodos. (Grassi, D. Trad.). (3a ed.). Bookman.

Zanella, L. C. H. (2013). Metodologia de pesquisa. (2a ed.), Departamento de Ciências da Administração/ UFSC.

Zangiski, M. A. S. G., Lima, E. P., \& Costa, S. E. G. (2009). Aprendizagem organizacional e desenvolvimento de competências: uma síntese a partir da gestão do conhecimento. Produto \& Produção, 10(1), 54-74.

Zonzini, A. L. (2014). Gestão do Conhecimento. Know How. 